\title{
Characterization of Material Stiffness on Injection Moulded Microspecimens Using Different Test Methods
}

\author{
Dietmar Drummer, Andreas Seefried, and Steve Meister \\ Institute of Polymer Technology, University Erlangen-Nuernberg, Am Weichselgarten 9, 91058 Erlangen, Germany \\ Correspondence should be addressed to Steve Meister; meister@lkt.uni-erlangen.de
}

Received 10 March 2014; Accepted 25 June 2014; Published 10 July 2014

Academic Editor: Steve Bull

Copyright (C) 2014 Dietmar Drummer et al. This is an open access article distributed under the Creative Commons Attribution License, which permits unrestricted use, distribution, and reproduction in any medium, provided the original work is properly cited.

\begin{abstract}
Injection moulding of polymer microparts can result in modified material behaviour due to process-induced changes in the internal properties. Thus, a transfer of the mechanical material properties in microparts, determined and valid on standardized test specimens, is only partially possible and should be verified on microtest specimens. This paper investigates both tensile and bending test methods for a suitable characterization of material stiffness in polymer microparts. For this purpose a down-scaled standard specimen is used and tested with different testing methods. The investigations reveal that the different testing methods result in comparable mechanical values. The effects of process-induced modified mechanical behaviour are observable in the investigated testing methods. Consequently, a microbending test is potentially a suitable method for characterizing material stiffness using microspecimens.
\end{abstract}

\section{Introduction}

Microsystems technology is reputed as a prospective key technology. The primary areas of application for polymer microparts are found in medical technology or biotechnology, as components of optical systems, microgears in microfluidics, and electronics and microelectromechanical systems $[1,2]$. Due to increasing requirements for these microcomponents, a rise in the demand for higher part quality and the reproducibility simultaneously occurs [3].

A reduction in part dimensions causes an increase in cooling that affects its morphological and mechanical properties $[4,5]$. Furthermore, long-term properties can also be affected [6-8]. To counteract this, new technologies and processing strategies have been developed: for example, a slow cooling of the melt using low conductive mould materials $[9,10]$ or a dynamic temperature control of the cavity [11-13] can be executed. A transfer of the mechanical material properties in microparts, determined and validated on standardized test specimens, is only partially possible [14]. Consequently, it is necessary to investigate the effects of part dimensions on the usable material properties [15-17]. The characterization of dimension-dependent mechanical properties is generally possible using different scaled tensile bars $[18,19]$. However, with decreasing part dimensions the standard deviation increases and in particular the characterization of the material's stiffness becomes more difficult.

The mechanical behaviour of a material is defined as the reaction of a mechanical load. Loads exerted onto a part lead to stress and a resulting deformation depending on the mechanical behaviour of the material and the amount and the direction of the force as well as the design of the part [20]. The deformation of polymers is divided into three superposed deformation components [20, 21]. (a) A purely elastic deformation takes place in polymers at very low loads. Under load the deformation occurs spontaneously and is completely reversible after discharge. (b) The viscous deformation is a function of time and is irreversible after discharge. (c) The combination of elastic and viscous deformation is called viscoelastic or relaxing deformation. Under a constant load, the component deformation becomes progressively lower. After discharge the deformation quickly occurs and then steadily slows down, after which it is finally reversible.

As described above, processing conditions can influence the mechanical properties of polymer materials. Molecular orientations, which are always existing in injection moulded 
parts, can increase the stiffness in the direction of the orientation and across to the orientation leading to converse results [22]. The crystalline structure also influences the mechanical behaviour, in the fact that an increasing degree of crystallinity leads to a higher degree of stiffness [23]. A homogeneous crystalline structure prevents a local concentration of stress and a potential part failure [24]. Residual stress as a result of inhomogeneous cooling can also lead to local stress concentrations, decreasing the material's stiffness $[25,26]$.

The environmental conditions during the material testing have an additional effect on measured values. According to ISO 291 room climate is standardized with a temperature at $23^{\circ} \mathrm{C}$ and a humidity of $50 \%$. Consequently, the test specimens have to be conditioned while taking the specific material properties and test conditions into account [20, 27]. A defined conditioning status is particularly needed for hygroscopic materials like polyamides due to decrescent stiffness with an increasing moisture content [21].

When designing and dimensioning polymer parts, the material behaviour under mechanical loads has to be known [28]. Based on standardized testing procedures the appropriate strength and respective deformation characteristics provide a comparison of polymer materials as well as a basis for the design of polymer parts. One important characteristic is the material stiffness, the modulus. Typical testing methods are the tensile tests according to ISO 527 and bending tests according to ISO $178[20,22]$. Different testing methods can produce the additional effect of leading slightly different measurement values. Jaroschek [29] showed with an amorphous polystyrene that the tensile modulus correlates with the bending modulus, whereas the tensile modulus for polypropylene and polyamide 66 is approximately $5 \%$ higher than the bending modulus. However, the difference between these testing methods is less important than the testing conditions, for example, humidity and temperature, and can be neglected.

The scope of this paper is to investigate testing methods for the suitable characterization of material stiffness in thermoplastic microparts. For this purpose a microtensile bar with 1:8 scaled dimensions is used and tested with three testing methods: a tensile test and two bending tests. To investigate processing and morphological influences an amorphous and two semicrystalline thermoplastics are used, which are injection moulded under different processing conditions.

\section{Experimental Section}

2.1. Materials. Three different thermoplastic polymers were investigated in the present study. An amorphous polycarbonate (PC, Makrolon OD2015, Bayer MaterialsScience AG) is used as a material without cooling-dependent crystalline structures and serves as a reference for the testing methods. Two semicrystalline polymers, a polyoxymethylene (POM, Hostaform C9021, Ticona $\mathrm{GmbH}$ ) and a polyamide 66 (PA66, Ultramid A3K, BASF SE), are used to investigate morphology-dependent effects on the measured values.

Table 1 shows manufacturer's data for the tensile and the bending modulus of the investigated materials. The PC has
TABLE 1: Material properties.

\begin{tabular}{lcccc}
\hline Characteristic & PC & POM & $\begin{array}{c}\text { PA66 } \\
\text { (dry) }\end{array}$ & $\begin{array}{c}\text { PA66 } \\
\text { (humid) }\end{array}$ \\
\hline $\begin{array}{l}\text { Tensile modulus [MPa] } \\
\quad 1 \mathrm{~mm} \mathrm{~min}^{-1}\end{array}$ & 2350 & 2850 & 3100 & 1100 \\
$\begin{array}{l}\text { Bending modulus [MPa] } \\
2 \mathrm{~mm} \mathrm{~min}^{-1}\end{array}$ & 2350 & 2700 & 2900 & $\mathrm{n} / \mathrm{a}$ \\
\hline
\end{tabular}

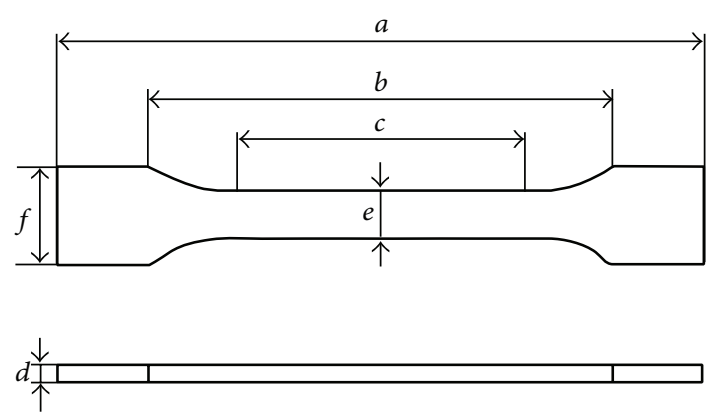

FIgURE 1: Geometry of the tensile bar.

the same values for the tensile and bending modulus, whereas the bending modulus of the PA66 and the POM is slightly lower than the tensile modulus. As discussed above, this effect is typical for these different testing methods.

2.2. Specimens. To investigate the mechanical behaviour of the materials a microtensile bar is used. The dimensions of the tensile bar have a ratio of 1:8 according to the standardized tensile bar according to EN ISO 3167 Type A. The design and dimensions of the tensile bar are shown in Figure 1 and Table 2. The shoulder lengths of the microtensile bar are extended to ensure a safe clamping during tensile testing.

2.3. Processing. For injection moulding an Arburg Allrounder 370U 700-30/30 injection moulding machine is utilized, equipped with a position-controlled screw with a diameter of $15 \mathrm{~mm}$. To vary the part's morphology and crystalline structure a variothermal process is implemented to alter the mould temperature. To achieve the dynamic mould temperature a variothermal temperature control system (type: SWTS 200, Single Temperiertechnik GmbH) is used. The system employs water as the circulating fluid and has a heating and cooling circuit-switching device. The heating circuit allows for a fluid temperature of up to $200^{\circ} \mathrm{C}$. The mould is maintained at a constant temperature for the purpose of processing stability, and only the temperature of the cavity inserts is actively controlled. These cavity inserts are constructed layer by layer from a steel powder using a rapid tooling process (LaserCusing, Concept Laser $\mathrm{GmbH}$ ). This manufacturing process allows for a complex design of cooling channels while also ensuring an optimized tempering of the cavity.

The combination of insulation from the master mould and conformal cooling channels are conducive to particularly rapid temperature changes in the cavity. This allows a mould 
TABLE 2: Dimensions of tensile bars.

\begin{tabular}{lcccccc}
\hline Tensile bar & $a[\mathrm{~mm}]$ & $b[\mathrm{~mm}]$ & $c[\mathrm{~mm}]$ & $d[\mathrm{~mm}]$ & $e[\mathrm{~mm}]$ & $f[\mathrm{~mm}]$ \\
\hline Standard & 170 & 108 & 80 & 4 & 10 & 20 \\
$1: 8$ & 28 & 13.5 & 10 & 0.5 & 1.25 & 2.5 \\
\hline
\end{tabular}

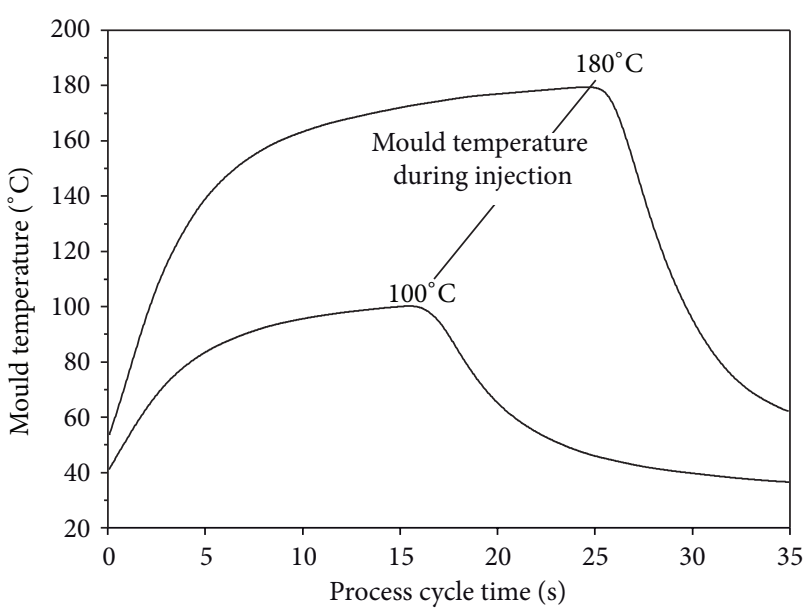

FIGURE 2: Mould temperatures during injection moulding to achieve varied morphology in the specimens (close-to-cavity measurement).

temperature, during injection moulding, to affect significantly the morphology development in the microspecimens. The mould temperature is measured by temperature sensors near the cavity. The curves of the temperature for the different mould temperatures during injection are shown in Figure 2. Relevant processing conditions for the three materials are shown in Table 3.

\subsection{Characterization}

2.4.1. Morphology and Crystallinity. The crystalline morphology was investigated on $10 \mu \mathrm{m}$ thick cuts using polarised light microscopy. These cuts were taken out from the middle of the tensile bars along the injection direction.

For crystallinity characterization, infrared microscopy (Advantage, Spectra Tech Inc., Shelton, CT, USA) was applied to the PA parts. Three transmission measurements of thin cuts were carried out on each part. The ratio $r$ of extinction of the absorbance bands at $1199 \mathrm{~cm}^{-1}$ for the crystalline part and of $1180 \mathrm{~cm}^{-1}$ for the amorphous part describes the degree of crystallinity, as shown by Kohan [30]. The ratio $r$ allows for an approximate calculation of the degree of crystallization with the following equation [31]:

$$
f(r)=-1.30591+20.0028 r-1.86991 r^{2} .
$$

The degree of crystallinity in the POM parts was characterized by differential scanning calorimetry (DSC) using a Q1000 (TA Instruments) with a heating rate of $10 \mathrm{~K} \mathrm{~s}^{-1}$ and a cooling rate of $20 \mathrm{~K} \mathrm{~s}^{-1}$. For $100 \%$ crystallinity, an enthalpy of $220 \mathrm{~J} \mathrm{~g}^{-1}$ was used [32].
2.4.2. Mechanical Testing. To determine the mechanical behaviour of the tensile bars three different tests were conducted: a tensile test as outlined by ISO 527-1 and a bending test according to ISO 178 (bending test 1) were carried out using a microtesting machine MicroTester (Instron Deutschland $\mathrm{GmbH}$ ). In addition, a second bending test was done on a thermomechanical analyser TMA Q400EM (TA Instruments). The setup of the varying testing methods is depicted in Figure 3. Due to the dimension of the 1:8 tensile bar, testing parameters must be adjusted, as shown in Table 4 . To determine the modulus, the measured values at a strain of $0.05 \%$ and $0.25 \%$ are used for the tensile test and the bending test 1 ; for bending test 2 , the values 0 and 0,1 are used. The maximum deformation in the bending test 1 was $3.5 \%$ due to the design constraint of the fixture; the tensile test is carried out until breaking of the specimen.

Due to the influence of water on the mechanical behaviour of the PA66 samples, these were conditioned before testing. For dry conditions the tensile bars were conditioned before testing in a vacuum oven at $70^{\circ} \mathrm{C}$. The moisture of the PA66 parts was verified with Karl Fischer titration before testing, with rendered values below $0.2 \mathrm{wt}-\%$.

\section{Results and Discussion}

3.1. Morphology. Due to the process conditions the morphology can be influenced. The injection moulded POM parts show typical polyhedral spherulites in the core and an oriented surface layer without spherulite structures (Figure 4). In addition, the morphology is less affected by the processing conditions. This is due to the POM's high rate and ability to crystallise. In contrast, the morphology of the PA66 parts is strongly affected by the processing conditions due to the material's slower crystallisation velocity. While the tensile bars injection moulded at $100^{\circ} \mathrm{C}$ show an amorphous structure with only single isolated spherulites, this can be attributed to thermal nucleation due to the high cooling rate. A higher mould temperature shows a more spherulitic morphology over the entire cross-section (Figure 5).

The degree of crystallinity is accompanied by the various effects on the morphological structure. As can be observed in Figure 6, the POM parts show nearly the same value. The average value decreases slightly with a higher mould temperature; however, this effect is less significant due to the deviation. The degree of crystallinity in the PA66 parts is affected more by processing (Figure 7), also evident in the morphological structure. While the parts injection moulded at $100^{\circ} \mathrm{C}$ show a low degree of crystallinity over the entire cross-section, a higher processing temperature increases the degree of crystallinity. In the surface area where the cooling develops first, a lower value of crystallinity exists which increases at the core of the specimen. 


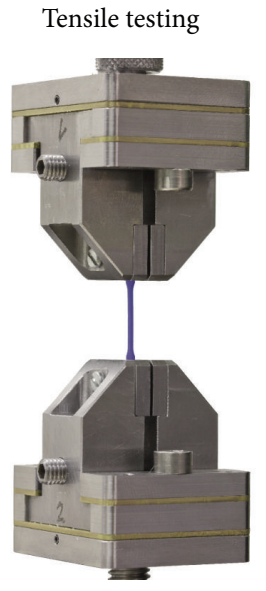

Machine: MicroTester

(a)
Bending test 1

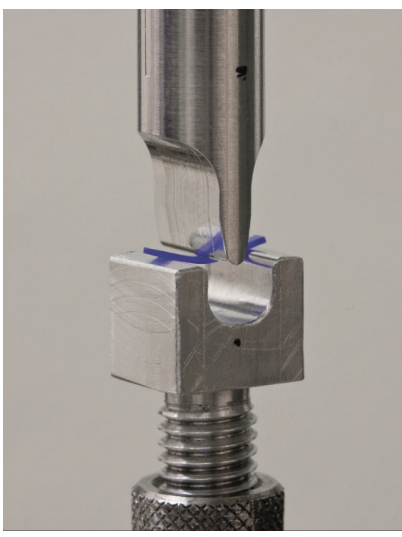

Machine: MicroTester

(b)
Bending test 2

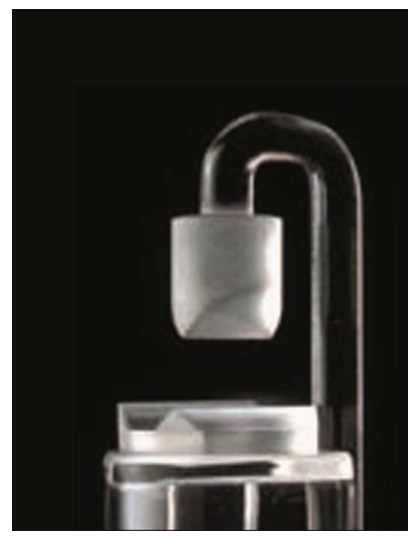

TMA Q400EM

(c)

FIGURE 3: Setup of the different testing methods (clamping devices for the tensile test (a) and bending test 1 (b) used Instron MicroTester and bending test 2 used TMA Q400EM (c)).
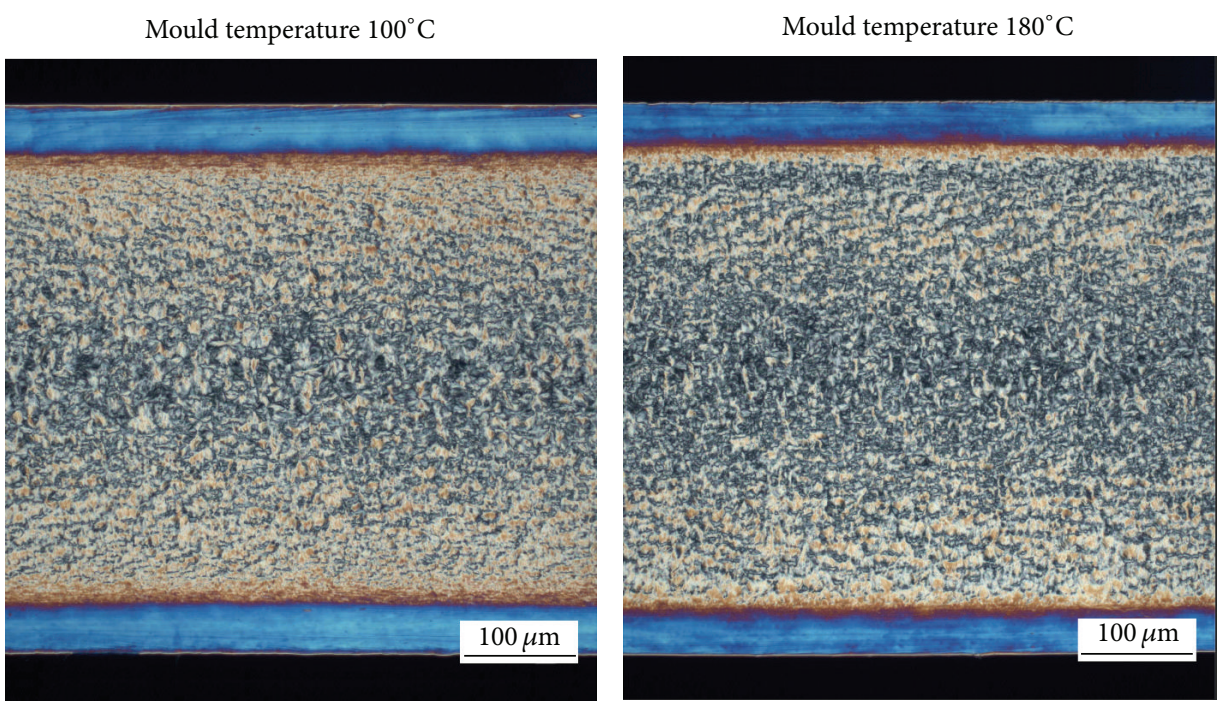

FIGURE 4: Morphology of the POM tensile bars.

TABle 3: Processing parameters.

\begin{tabular}{lccc}
\hline Material & Melt temperature $\left[{ }^{\circ} \mathrm{C}\right]$ & Mould temperature during injection $\left[{ }^{\circ} \mathrm{C}\right]$ & ${\text { Melt flow velocity }\left[\mathrm{cm}^{3} \mathrm{~s}^{-1}\right]}$ \\
\hline PA 66 & 290 & $100 / 180^{1}$ & 18 \\
POM & 210 & $100 / 180^{1}$ & 18 \\
PC & 300 & $100 / 180^{1}$ & 18 \\
\hline
\end{tabular}

${ }^{1}$ See also Figure 2.

TABLE 4: Tensile test parameters.

\begin{tabular}{lccc}
\hline Parameter & Tensile test & Bending test 1 & Bending test 2 \\
\hline Clamping length/support distance $[\mathrm{mm}]$ & 11.6 & 10 & 5 \\
Test velocity [mm min $^{-1}$ ] & 0.125 & 0.2 & $0.2 \mathrm{~N}^{1}$ \\
Measuring range for module calculation [\%] & $0.05-0.25$ & $0.05-0.25$ & $0-0.1$ \\
Maximum Elongation [\%] & break & 3.5 & - \\
\hline
\end{tabular}

\footnotetext{
${ }^{1}$ Force controlled with an elongation of $0.1 \%$.
} 

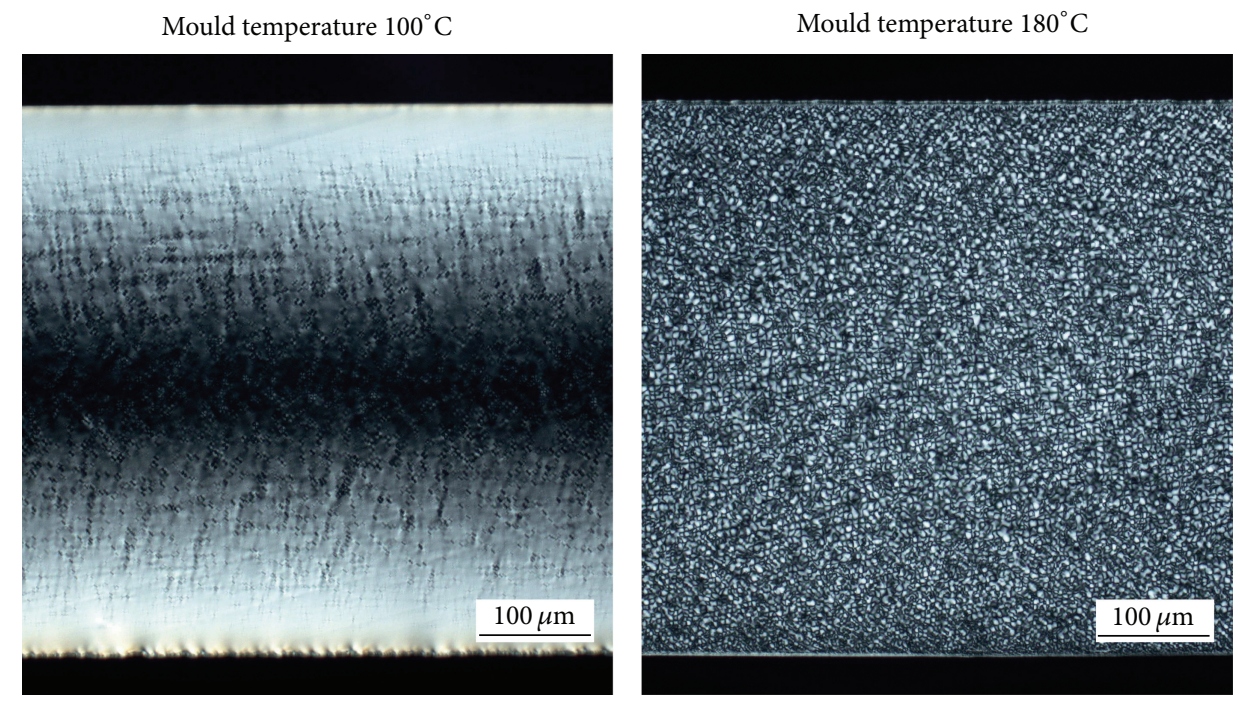

Figure 5: Morphology of the PA66 tensile bars.

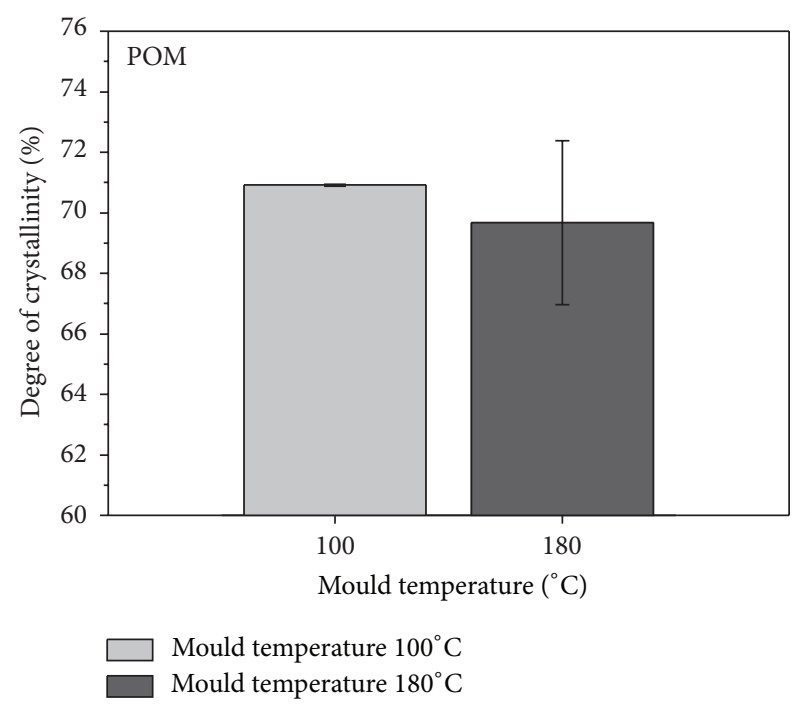

FIgURE 6: Degree of crystallinity in POM tensile bars with respect to mould temperature.

\subsection{Mechanical Characterization}

3.2.1. Polycarbonate (PC). Figure 8 shows representative stress/strain curves of the tensile test and the bending test 1 of the PC material. It can be seen that for low strain rates the curves correlate. At higher strain rates the tensile test shows a typical yielding of the material, and the bending test leads, due to the overlapping stress conditions, to an increasing value. Furthermore, the bending test is stopped at an elongation of $3.5 \%$, while the microbending test reveals additional characteristics like yield or elongation at break.

For both the tensile and the bending modulus the manufacturer defines a value of $2350 \mathrm{MPa}$ for the PC. Figure 9 shows the comparison between the measured values of the PC with the scaled tensile bars used. The different test methods

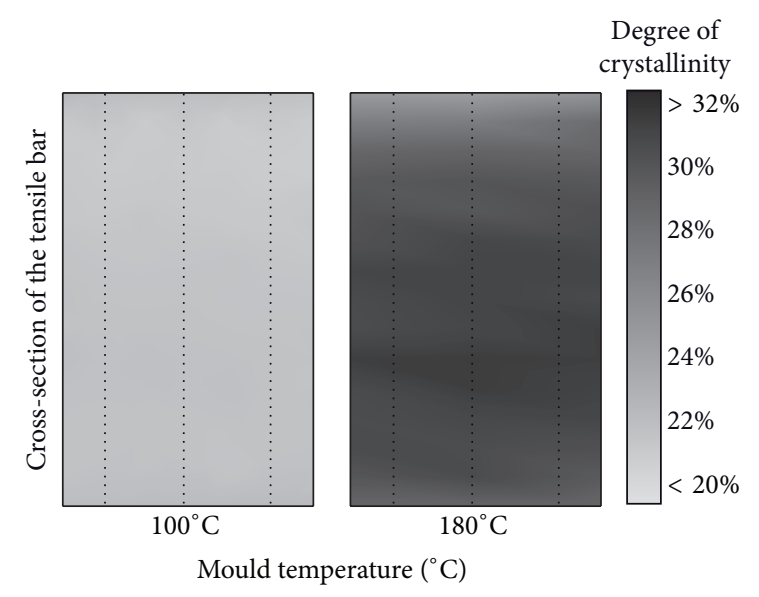

FIGURE 7: Degree of crystallinity in PA66 in the middle of the tensile bars with respect to the mould temperature (3 measuring points in the flow direction and 15 measuring points across the thickness with a measuring area of $200 \times 20 \mu \mathrm{m}$ ).

show no significant variation in the measured modulus. Only the deviation of the tensile modulus is distinctly higher (ca. $20 \%$ ) whereas the deviation in the bending test is less than $5 \%$. This shows that bending tests on small test specimens can generate comparable mechanical properties and reproducible values as well.

3.2.2. Polyoxymethylene (POM). As previously discussed, the mechanical behaviour of the POM can be affected by the processing conditions. As a consequence the modulus varies depending on the processing conditions used (Figure 10). The specimens injection moulded with a constant mould tempering reveal a higher modulus than the specimens manufactured with a dynamic mould tempering. This can be due to the slightly higher degree of crystallinity and the modified molecular orientation. However, the bending tests 


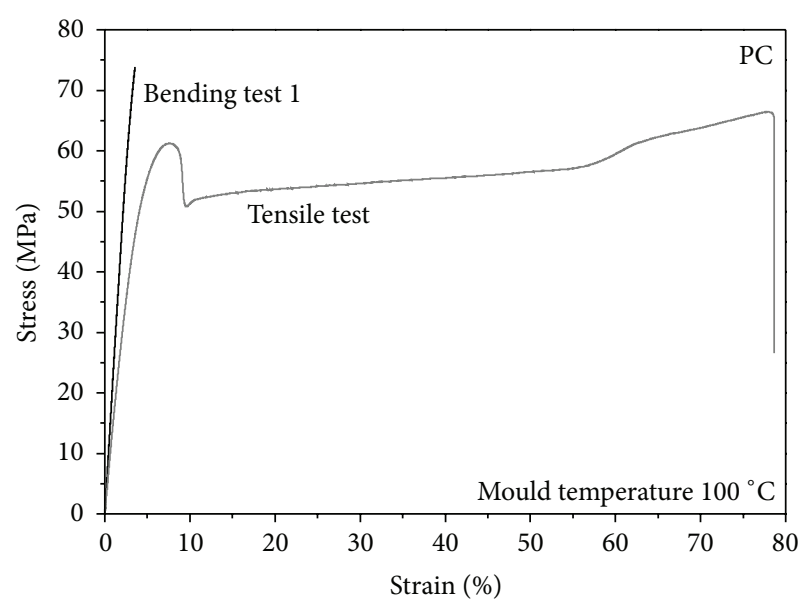

FIGURE 8: Representative stress/strain curves of bending and tensile test of PC specimens.

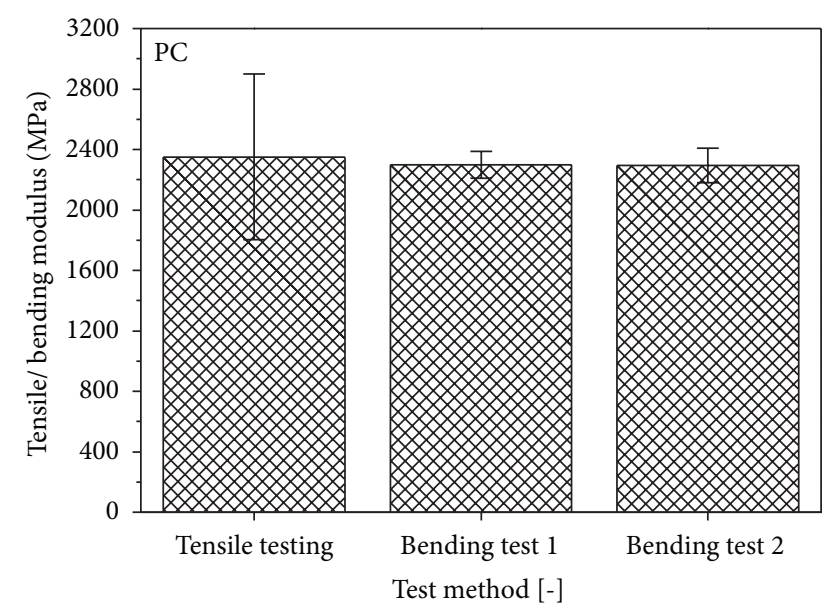

Mould temperature $100^{\circ} \mathrm{C}$

Figure 9: Tensile and bending modulus of the PC specimens.

show the same or slightly higher modulus than the tensile test. This is in contrast to the effects observed by Jaroschek [29], where bending tests result in values $5 \%$ lower. This can be due to slightly more precise measurements in the bending test and particularly the absence of clamping effects on the small specimens during tensile testing. In addition, the deviation of the tensile test results is greater than that of the bending tests, which suggests a reproducible and robust test for material stiffness with small parts.

3.2.3. Polyamide 66 (PA66). The PA66 material is strongly affected by the processing conditions, which leads to a higher modulus of the material. This can be seen in the results of the tensile test as well as the bending tests. However, as already seen for the POM material the bending tests result in slightly higher values. In dry conditions (Figure 11) the difference is about $400 \mathrm{MPa}$, whereas in humid conditions (Figure 12) the difference is less significant. This can be due to two effects: the aforementioned absence of clamping effects in the

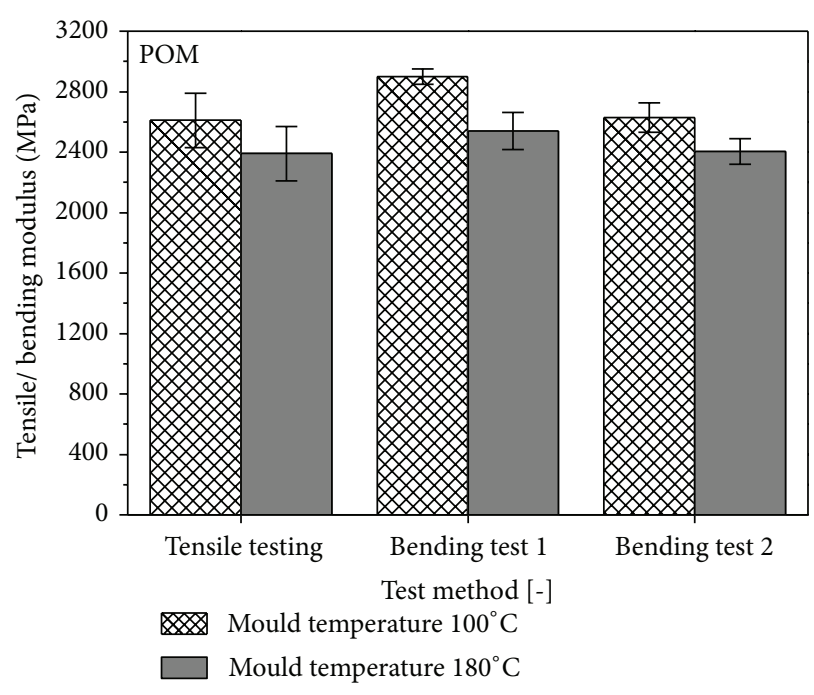

FIGURE 10: Tensile and bending modulus of the POM specimens.

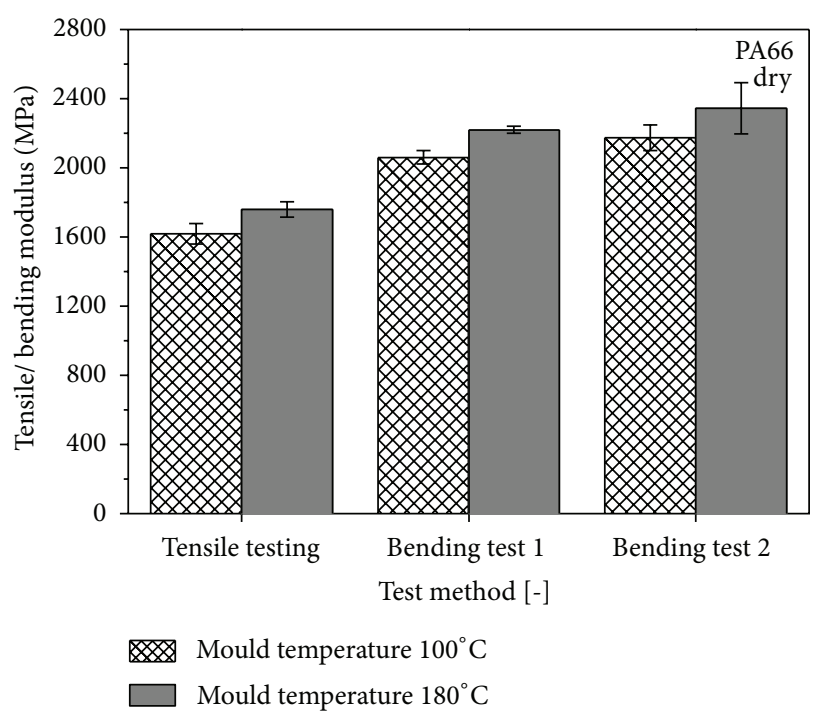

FIGURE 11: Tensile and bending modulus of the PA66 specimens, dry conditioned.

bending test and also quicker test preparation and alignment of the specimen, which reduces the failure due to moisture absorption. This interaction of moisture absorption and its effect on the modulus measured was already discussed in [18]. Testing humid conditioned PA66 parts shows a reduced influence of testing methods, which confirms the previously mentioned failure due to moisture absorption.

\section{Conclusion}

Reduced dimensions in microinjection moulded parts affect both internal structures and resulting mechanical properties. A transfer of the mechanical material properties in microparts determined and valid on standardized test specimens is only partially possible, as previously investigated [19]. Consequently, different testing methods were investigated to 


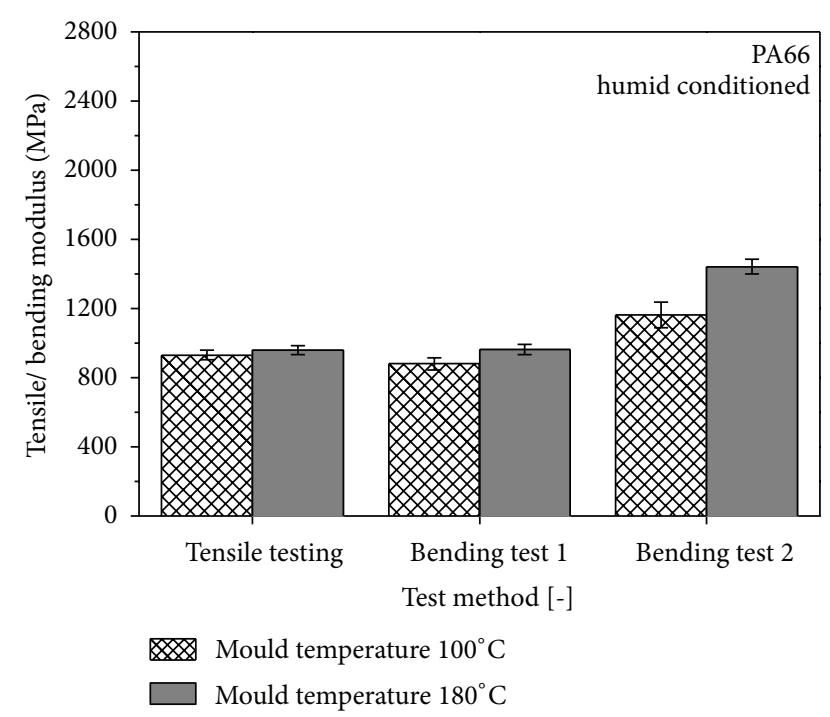

FIgURE 12: Tensile and bending modulus of the PA66 specimens, humid conditioned.

characterize the material stiffness in microparts. A comparison between the different testing methods allows for the following statements.

(i) The bending test is a valid method for characterizing the stiffness (bending modulus) on microtensile bars. Particularly amorphous polymers, like PC, show no difference between tensile and bending modulus. Furthermore, the deviation decreases when carrying out a bending test. This indicates a more reliable mechanical characterization.

(ii) Process or morphology-dependent changes in mechanical behaviour, which lead to a modified tensile modulus, affect the bending modulus as well. Semicrystalline polymers like PA66 and POM reveal a process-dependent modified inner structure, which changes the mechanical properties of the material. These changes can be determined with a tensile test as well as a bending test.

(iii) The characterization of the modulus on microspecimens using a bending test can reduce error interferences. This can be due to the absence of clamping effects in a tensile test and also a faster preparation of the conditioned materials, which can change the mechanical characteristics as a result of moisture absorption.

A final conclusion to be drawn may be that microbending can be a suitable testing method for characterizing material stiffness in microparts. However, this method cannot substitute a tensile test due to default characterization of yield behaviour. Furthermore, microbending tests can also be applied for mechanical characterization of small samples locally taken out of larger polymer parts.

\section{Conflict of Interests}

The authors declare that there is no conflict of interests regarding the publication of this paper.

\section{Acknowledgments}

The authors would like to thank the Bavarian Research Foundation for funding this work. The authors also extend their gratitude to their industrial partners Werkzeugbau Hofmann GmbH, Oechsler AG, Single Temperiertechnik GmbH, hotec $\mathrm{GmbH}$, Arburg GmbH \& Co. KG, Sabic Europe, Bayer MaterialsScience AG, and BASF SE for providing the equipment and material. The authors also acknowledge support by Deutsche Forschungsgemeinschaft and FriedrichAlexander-Universität Erlangen-Nürnberg within the funding programme Open Access Publishing.

\section{References}

[1] D. M. Bibber, "Micro molding challenges", in Proceedings of the SPE Annual Technical Conference (ANTEC '04), pp. 3703-3711, Chicago, Ill, USA, 2004.

[2] A. K. Angelov and J. P. Coulter, "Micromolding product manufacture: a progress report," in Proceedings of the Annual Technical Conference (ANTEC '04), pp. 748-751, Chicago, Ill, USA, May 2004.

[3] O. Pfirrmann and M. Astor, Trendreport MikrosystemtechnikInnovative Ideen rund um die Mikrosystemtechnik, Prognos AG, Basel, Switzerland, 2006.

[4] A. M. Tom, G. S. Layser, and J. P. Coulter, "Mechanical property determination of micro injection molded tensile test specimens," in SPE Proceedings ANTEC, pp. 2541-2545, Charlotte, Calif, USA, 2006.

[5] T. Nguyen-Chung, C. Löser, G. Jüttner, M. Obadal, T. Pham, and M. Gehde, "Morphology analysis of injection molded micro-parts," International Journal of Plastics Technology, vol. 7, no. 3, pp. 86-114, 2011.

[6] S. Meister, A. Jungmeier, and D. Drummer, "Long-term properties of injection-molded micro-parts: influence of part dimensions and cooling conditions on aging behavior," Macromolecular Materials and Engineering, vol. 297, no. 10, pp. 994-1004, 2012.

[7] S. Meister and D. Drummer, "Affecting the ageing behaviour of injection moulded micro-parts using variothermal mould tempering," Advances in Mechanical Engineering, vol. 2013, Article ID 407964, 7 pages, 2013.

[8] S. Meister and D. Drummer, "Dimension-dependent long-term properties of injection molded micro parts," in Proceedings of the SPE ANTEC, Las Vegas, Nev, USA, 2014.

[9] D. Schmiederer and E. Schmachtenberg, "Einflüsse auf die Eigenschaften kleiner und dünnwandiger Spritzgussteile," Zeitschrift Kunststofftechnik, vol. 2, no. 5, pp. 1-21, 2011.

[10] A. Lurz and E. Schmachtenberg, "Influences on the properties of small and thin-walled in-jection molded parts-Part 2: Importance of the thermal conductivity of the mold material," Journal of Plastics Technology, vol. 4, no. 1, pp. 1-18, 2008.

[11] T. Walter, W. Schinköthe, W. Ehrfeld, C. Schaumburg, and L. Weber, "Injection moulding of microstructures with inductive mould heating," in Proceedings of the 16. Stuttgarter KunststoffKolloquium, pp. 1-10, Stuttgart, Germany, 1999. 
[12] J. Giessauf, G. Pillwein, and G. Steinbichler, "Variotherm temperature control is fit for production," Kunststoffe International, vol. 98, no. 8, pp. 57-62, 2008.

[13] D. Drummer, K. Gruber, and S. Meister, "Alternating temperature technology controls parts properties," Kunststoffe International, vol. 101, no. 4, pp. 25-27, 2011.

[14] E. Haberstroh and M. Brandt, "Determination of mechanical properties of thermoplastics suitable for micro systems," Macromolecular Materials and Engineering, vol. 287, no. 12, pp. 881888, 2002.

[15] T. Koch and S. Seidler, "Mechanical properties of microinjection moulded components," Macromolecular Symposia, vol. 181, no. 1, pp. 499-506, 2002.

[16] G. R. Greenway, P. S. Allan, and P. R. Hornsby, "The characterisation and physical testing of micro-mouldings," in Proceedings of the SPE Annual Technical Conference (ANTEC '03), pp. 19951999, Nashville, Tenn, USA, 2003.

[17] A. Jungmeier, D. Drummer, and G. W. Ehrenstein, "Optimization strategies for micro-parts," Kunststoffe International, vol. 101, no. 7, pp. 50-53, 2011.

[18] S. Meister, K. Vetter, G. W. Ehrenstein, and D. Drummer, "Measurement of mechanical material properties for microparts on injection moulded micro tensile bars," Journal of Plastics Technology, vol. 9, no. 1, pp. 74-99, 2013.

[19] S. Meister and D. Drummer, "Influence of manufacturing conditions on measurement of mechanical material properties on thermoplastic micro tensile bars," Polymer Testing, vol. 32, no. 2, pp. 432-437, 2013.

[20] W. Grellmann and S. Seidler, Polymer Testing, Hanser, Munich, Germany, 2007.

[21] G. W. Ehrenstein, Polymeric Materials-Structure, Properties, Applications, Hanser, Munich, Germany, 2001.

[22] G. W. Ehrenstein, Mit Kunststoffen Konstruieren, Hanser, Munich, Germany, 2nd edition, 2007.

[23] H. W. Starkweather and R. E. Brooks, "Effect of spherulites on the mechanical properties of nylon 66," Journal of Applied Polymer Science, vol. 1, no. 2, pp. 236-239, 1959.

[24] G. Wübken, Einfluss der Verarbeitungsbedingungen auf die innere Struktur thermoplastischer Spritzgussteile unter besonderer Berücksichtigung der Abkühlverhältnisse [Ph.D. thesis], RWTH Aachen, 1974.

[25] J. Schnieders, Analyse der fertigungs-und prozesseinflüsse auf die spannungsrissbildung beim fügen amorpher thermoplaste mittels heizelement [Ph.D. thesis], University Paderporn, 2004.

[26] S.-C. Chen, H.-S. Peng, L.-T. Huang, and M.-S. Chung, "Investigations of the tensile properties on polycarbonate thin-wall injection molded parts," Journal of Reinforced Plastics and Composites, vol. 22, no. 5, pp. 479-494, 2003.

[27] R. Brown, Handbook of Polymer Testing: Physical Methods, Marcel Dekker, New York, NY, USA, 1999.

[28] T. Brinkmann, Produktentwicklung mit Kunststoffen, Hanser, Munich, Germany, 4th edition, 2010.

[29] C. Jaroschek, "The end of the flexual modulus," Journal of Plastics Technology, vol. 8, pp. 515-524, 2012.

[30] M. I. Kohan, Nylon Plastics Handbook, Hanser, Munich, Germany, 1995.

[31] A. Jungmeier, Structure and properties of injection moulded thermoplastic micro-parts [Ph.D. thesis], University ErlangenNuremberg, 2010.

[32] G. W. Ehrenstein, G. Riedel, and P. Trawiel, Thermal Analysis of Plastics: Theory and Practice, Hanser, Munich, Germany, 2nd edition, 2004. 

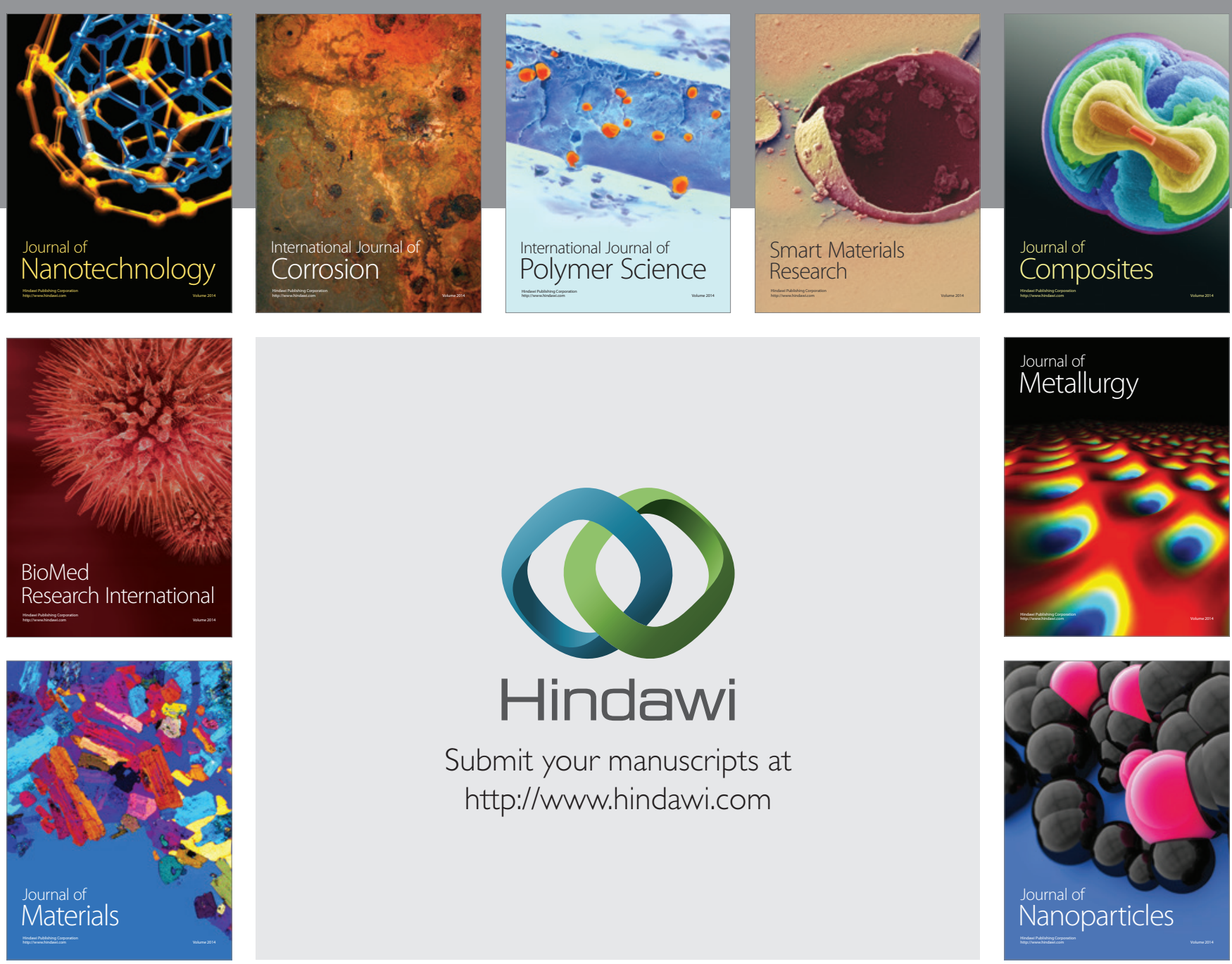

Submit your manuscripts at http://www.hindawi.com
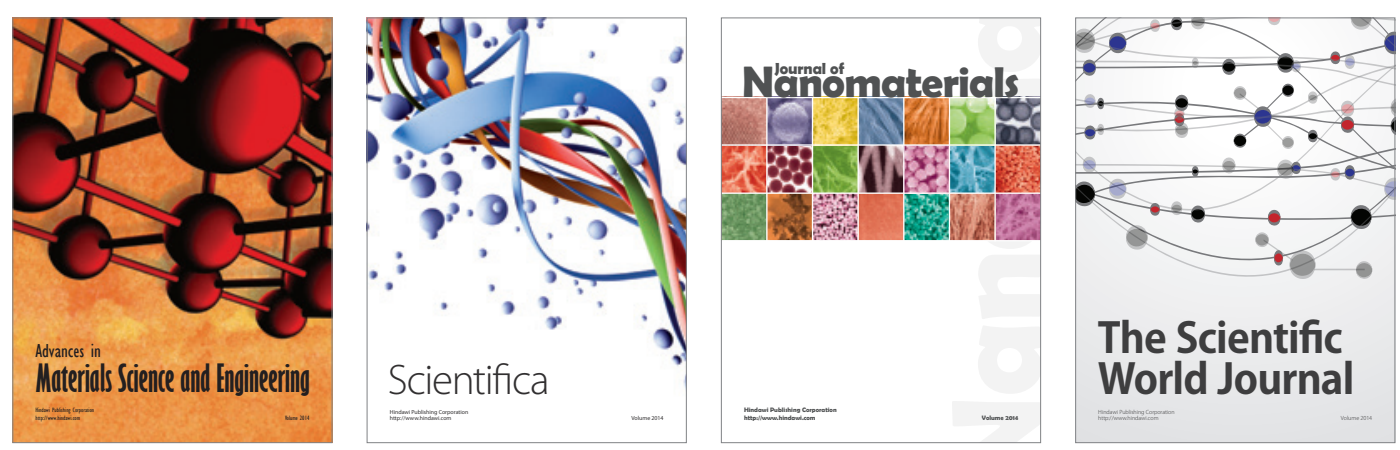

\section{The Scientific World Journal}
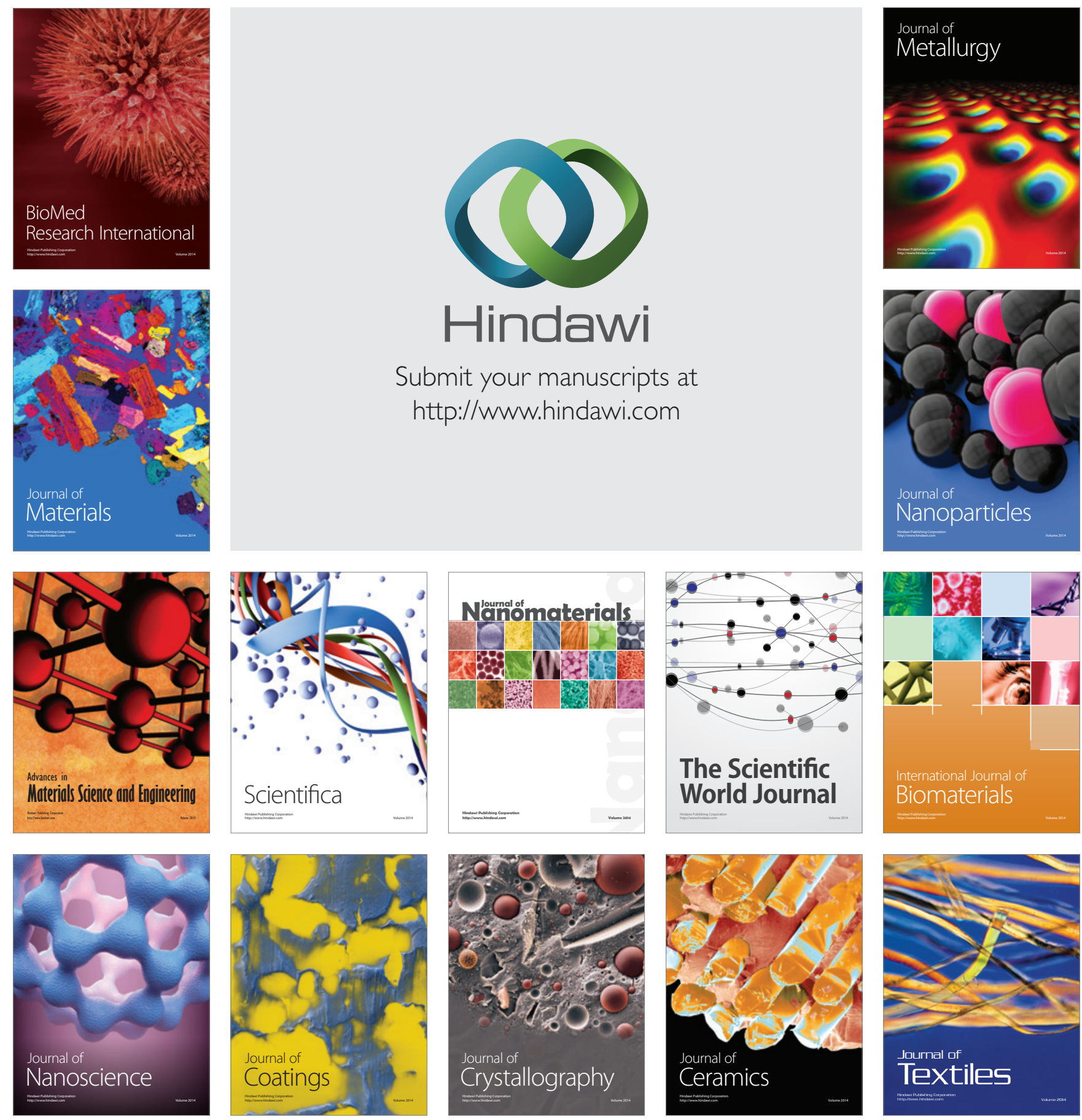